\title{
Biodegradation of Graphene Materials Catalyzed by Human Eosinophil Peroxidase
}

Rajendra Kurapati, ${ }^{1, \#}$ Cristina Martìn, ${ }^{1, \#}$ Vincenzo Palermo, ${ }^{2,3}$ Yuta Nishina,,${ }^{4,5}$ Alberto Bianco ${ }^{1 *}$

${ }^{1}$ University of Strasbourg, CNRS, Immunopathology and therapeutic chemistry, UPR 3572, 67000 Strasbourg, France. E-mail: a.bianco@ibmc-cnrs.unistra.fr

${ }^{2}$ Industrial and Materials Science, Chalmers University of Technology, 41258 Goteborg, Sweden

${ }^{3}$ Istituto per la Sintesi Organica e la Fotoreattività, CNR, 40129 Bologna, Italy

${ }^{4}$ Graduate School of Natural Science and Technology, Okayama University, Okayama, Japan

${ }^{5}$ Research Core for Interdisciplinary Sciences (RCIS), Okayama University, Okayama, Japan

${ }^{\#}$ These authors contributed equally to this work

Abstract: Understanding the biodegradability of graphene materials by the action of oxidative enzymes secreted by the immune cells is essential for developing applicable biomedical products based on graphene materials. Herein, we demonstrate the biodegradation of graphene oxide (GO) by recombinant eosinophil peroxidase (EPO) enzyme extracted from human eosinophils in the presence of a low concentration of hydrogen peroxide and $\mathrm{NaBr}$. We compared the degradation capability of the enzyme on three different GO samples containing different degrees of oxygen functional groups on their graphenic lattices. EPO succeeded in degrading the three tested GO samples within $90 \mathrm{~h}$ treatment. Raman spectroscopy and transmission electron microscopy analyses provided clear-cut evidence for biodegradation of GO by EPO catalysis. Our results provide more insights into a better understanding of biodegradation of graphene materials, helping to the design of future biomedical products based on these carbon nanomaterials. 


\section{Introduction}

Graphene family materials (GFMs), including graphene, graphene oxide, or carbon nanotubes, have been increasingly attracting attention in electronics, energy, composites including biomedical applications due to their unique chemicophysical properties. ${ }^{1}$ Because of that, the presence of GFMs in the environment is constantly increasing. This fact alarms to interrogate the role of GFMs on environment and health contexts. Several studies have been carried out to understand the cytotoxicity of these GFMs both in vitro and in vivo models. ${ }^{2}$ However, the biodegradation ability of the GFMs has not been studied enough until now, despite degradation capacity is a crucial parameter to determine the fate of any foreign material in vivo. ${ }^{2,3}$ Some examples reported in the literature studied the biodegradation of GFMs by enzymatic catalysis of peroxidases in the presence of hydrogen peroxide, where peroxidase enzymes are secreted by immune cells like activated neutrophils, macrophages, etc. ${ }^{4-7}$ There are also plant enzymes like horseradish peroxidase (HRP) and fungal enzyme-like lignin peroxidase, which can also degrade GFMs and other 2D materials. ${ }^{5-11}$ Initially, the degradation of the GO materials was demonstrated using HRP. ${ }^{9}$ We then demonstrated that covalently functionalized GO with specific ligands enhanced the degradation by HRP in the presence of hydrogen peroxide. Alternatively, myeloperoxidase (MPO) extracted from neutrophils is able to degrade highly dispersible GO materials within $24 \mathrm{~h}^{4}$ Girish et al. showed that the degradation of carboxylated graphene sheets (acid-treated) could be degraded in vivo within macrophages due to action of MPO. ${ }^{12}$ Kurapati et al. have recently demonstrated that pristine graphene sheets can be degraded by recombinant MPO and in vitro by neutrophil secreted MPO. ${ }^{6}$ Finally, we have synthesized a new biodegradable multifunctional GO hybrid for targeted cancer therapy by functionalizing the GO surface with the chemotactic peptide fMLP, which is known to interact with the formyl peptide receptor expressed in cervical carcinoma cells. $^{13}$ For the first time, the hybrid nanomaterial was capable of inducing neutrophil degranulation with no prior activation of the cells.

Eosinophils are one of the most important immune cells, which secrete EPO from their granulocytes. These cells play a major role when there is an allergic reaction in the body due to some parasitic infections. Then, EPO is responsible for death of the parasites by its enzymatic catalysis. ${ }^{14}$ However, whether EPO could also degrade GO like MPO secreted by neutrophils has not been reported yet. Previously, Kagan et al. described that oxidized single-wall carbon nanotubes (SWCNTs) were completely degraded by EPO within $90 \mathrm{~h}$ treatment. ${ }^{15}$ Hereby, we 
interrogate the ability of recombinant EPO extracted from human eosinophils to oxidize different GO materials in the presence of $\mathrm{H}_{2} \mathrm{O}_{2}$ and $\mathrm{NaBr}$. EPO produces potential oxidants such as $\mathrm{HOBr}$ and reactive radical intermediates named Compound I and Compound II with high redox potential, which could essentially oxidize the GO. The degradation of GO samples was followed by transmission electron microscopy and Raman spectroscopy. This work reports for the first time the biodegradation ability of GO by EPO.

\section{Results and discussion}

Eosinophils play a key role in the innate immune system by fighting against infections caused by multicellular parasites. ${ }^{16,17}$ They play also an important role in controlling the mechanisms associated with asthma and allergy. ${ }^{16}$ The inflamed eosinophils release EPO from their granulocytes exerting diverse functions during different diseased states including killing of the parasites. ${ }^{14} \mathrm{EPO}$ causes the oxidation of $\mathrm{Cl}^{-}, \mathrm{Br}-, \mathrm{I}^{-}, \mathrm{SCN}^{-}$by reacting with hydrogen peroxide leading to the formation of hypohalous acids ( $\mathrm{HOCl}, \mathrm{HOBr}, \mathrm{HOI}, \mathrm{HOSCN}$, respectively), which possess much strong antimicrobial activity compared to the reactive intermediates of EPO (e.g. Compound I and Compound II). For interrogating whether EPO could degrade GO sheets, three different GO samples were chosen from three different sources, namely GO 1, GO 2 and GO 3. GO 1 was obtained directly as an aqueous suspension by a modified Hummers method. ${ }^{18,19}$ GO 3 was also produced by a modified Hummers method, in which the oxidation degree of graphite is carefully controlled resulting in a fewer number of defects compared to typical GO. ${ }^{20,21} \mathrm{GO} 2$ sample is a commercially available powder from Grupo Antolin, synthesized by oxidation of carbon nanofibers using sodium nitrate in sulfuric acid at $0{ }^{\circ} \mathrm{C} .{ }^{22}$ XPS analysis showed that the percentage of graphitic $\mathrm{sp}^{2}$ carbon are $46 \%, 47 \%$ and $48 \%$ for GO 1, GO 2 and GO 3, respectively (Table 1), while, the percentages of the carboxylic groups are 3.0\%, 1.5\% and 1.0\% for GO 1, GO 2 and GO 3, respectively. XPS results suggest that GO 3 has slightly higher graphitic regions and lower defects compared to GO 1 and GO 2. Zeta potential, namely surface charge, plays crucial role in the colloidal stability of nanomaterials. The measured values of zeta potential corresponded to $-42.3,-41.8$, and $-40.0 \mathrm{mV}$ for GO 1, GO 2, and GO 3, respectively. In addition, the size of GO 3 sheets are much smaller $(\sim 0.6 \mu \mathrm{m})$ compared to GO 1 and GO 2, which are larger than $1 \mu \mathrm{m} .{ }^{4}$ 
Table 1: XPS results for GO 1, GO 2, and GO 3 samples, respectively.

\begin{tabular}{|l|l|l|l|}
\hline Sample & Group & \multicolumn{1}{|c|}{$\begin{array}{c}\text { Peak Binding Energy } \\
(\mathrm{eV})\end{array}$} & Atomic \% \\
\hline \multirow{5}{*}{ GO 1* } & $\mathrm{C}-\mathrm{O}$ & 286.9 & 43.0 \\
\cline { 2 - 4 } & $\mathrm{C}=\mathrm{C}, \mathrm{C}-\mathrm{C}, \mathrm{C}-\mathrm{H}$ & 284.6 & 46.0 \\
\cline { 2 - 4 } & $\mathrm{C}=\mathrm{O}$ & 288.2 & 8.0 \\
\cline { 2 - 4 } & $\mathrm{C}=\mathrm{O}(\mathrm{OH})$ & 289.3 & 3.0 \\
\hline \multirow{5}{*}{ GO $2^{*}$} & $\mathrm{C}-\mathrm{O}$ & 286.9 & 42.0 \\
\cline { 2 - 4 } & $\mathrm{C}=\mathrm{C}, \mathrm{C}-\mathrm{C}, \mathrm{C}-\mathrm{H}$ & 284.75 & 47.0 \\
\cline { 2 - 4 } & $\mathrm{C}=\mathrm{O}$ & 288.38 & 9.6 \\
\cline { 2 - 4 } & $\mathrm{C}=\mathrm{O}(\mathrm{OH})$ & 289.6 & 1.5 \\
\hline GO 3 & $\mathrm{C}-\mathrm{O}$ & 286.7 & 45.0 \\
\cline { 2 - 4 } & $\mathrm{C}=\mathrm{C}, \mathrm{C}-\mathrm{C}, \mathrm{C}-\mathrm{H}$ & 284.6 & 48.0 \\
\cline { 2 - 4 } & $\mathrm{C}=\mathrm{O}$ & 288.37 & 6.0 \\
\cline { 2 - 4 } & $\mathrm{C}=\mathrm{O}(\mathrm{OH})$ & 289.6 & 1.0 \\
\hline
\end{tabular}

*X-ray photoelectron spectroscopy analysis data for $\mathrm{GO} 1$ and $\mathrm{GO} 2$ are taken from our published articles ${ }^{4}$, 19

Next, to mimic the EPO enzymatic oxidation environment, EPO was mixed with the pre-dispersed GO samples in phosphate buffer solution, where $\mathrm{H}_{2} \mathrm{O}_{2}$ and $\mathrm{NaBr}$ were added every hour up to 90 $\mathrm{h}$ (in total). EPO was refreshed every $12 \mathrm{~h}$ due to the loss of its enzymatic activity. The cationic nature of the enzymes (EPO is a protein rich in arginine) and the negative surface charge of GO sheets in the aqueous media likely leads to the formation of an electrostatic complex, similarly to the interaction between MPO and GO sheets or oxidized CNTs. ${ }^{4,} 17$ The degradation of GO sheets was firstly evidenced by the loss of the brownish color of the GO suspensions after the treatment with EPO for $90 \mathrm{~h}$. The brownish color of GO 1 and GO 2 was completely lost after $90 \mathrm{~h}$ EPO treatment, while the incubation with $\mathrm{H}_{2} \mathrm{O}_{2}$ alone (control) of GO 1 and $\mathrm{GO} 2$ preserved the color unchanged, confirming the degradation of the GO sheets by EPO. In the case of GO 3, the color change was not evident even after $90 \mathrm{~h}$ treatment, likely due to an incomplete oxidation or degradation of GO 3. Similar type of color loss was observed previously after treating GO 1 and GO 2 with MPO for $24 \mathrm{~h}^{4}$

The degradation of the sheets was then assessed by TEM (Figure 1). TEM images showed that GO sheets lost their characteristic shape of the two dimensional structure as degradation reaction proceeds. Especially, GO 1 and GO 2 sheets (Figure 1B and 1E, respectively) completely lost their original morphology after $40 \mathrm{~h}$ of the treatment with the enzyme compared with their control 
samples at $0 \mathrm{~h}$ (Figure 1A and 1D, respectively). EPO treatment resulted in a completely holey GO 1 and GO 2 sheets. Numerous short fragments were also observed. This morphology is very similar to the previously observed holey GO after $15 \mathrm{~h}$ of MPO treatment in the presence of $\mathrm{H}_{2} \mathrm{O}_{2}$ and $\mathrm{NaCl}^{4}{ }^{4}$ After $90 \mathrm{~h}$ of EPO treatment, most of the GO 1 and GO 2 sheets were converted into nanoscale fragments as shown in Figure $1 \mathrm{C}$ and $1 \mathrm{~F}$, respectively. In the case of GO 3, the degradation of the sheets was also evident after 40 and $90 \mathrm{~h}$ of treatment (Figure 1H and 1I, respectively). Again holey GO sheets were visualized after EPO treatment. In addition, the treatment of the three $\mathrm{GO}$ samples only in the presence of $\mathrm{H}_{2} \mathrm{O}_{2}$ did not result in the degradation of the GO sheets as shown in Figure 2. These results are in agreement with previous reports where oxidation/degradation of GO was not occurring with only $\mathrm{H}_{2} \mathrm{O}_{2}$ treatment, confirming the key role of the enzyme. ${ }^{4}$ 


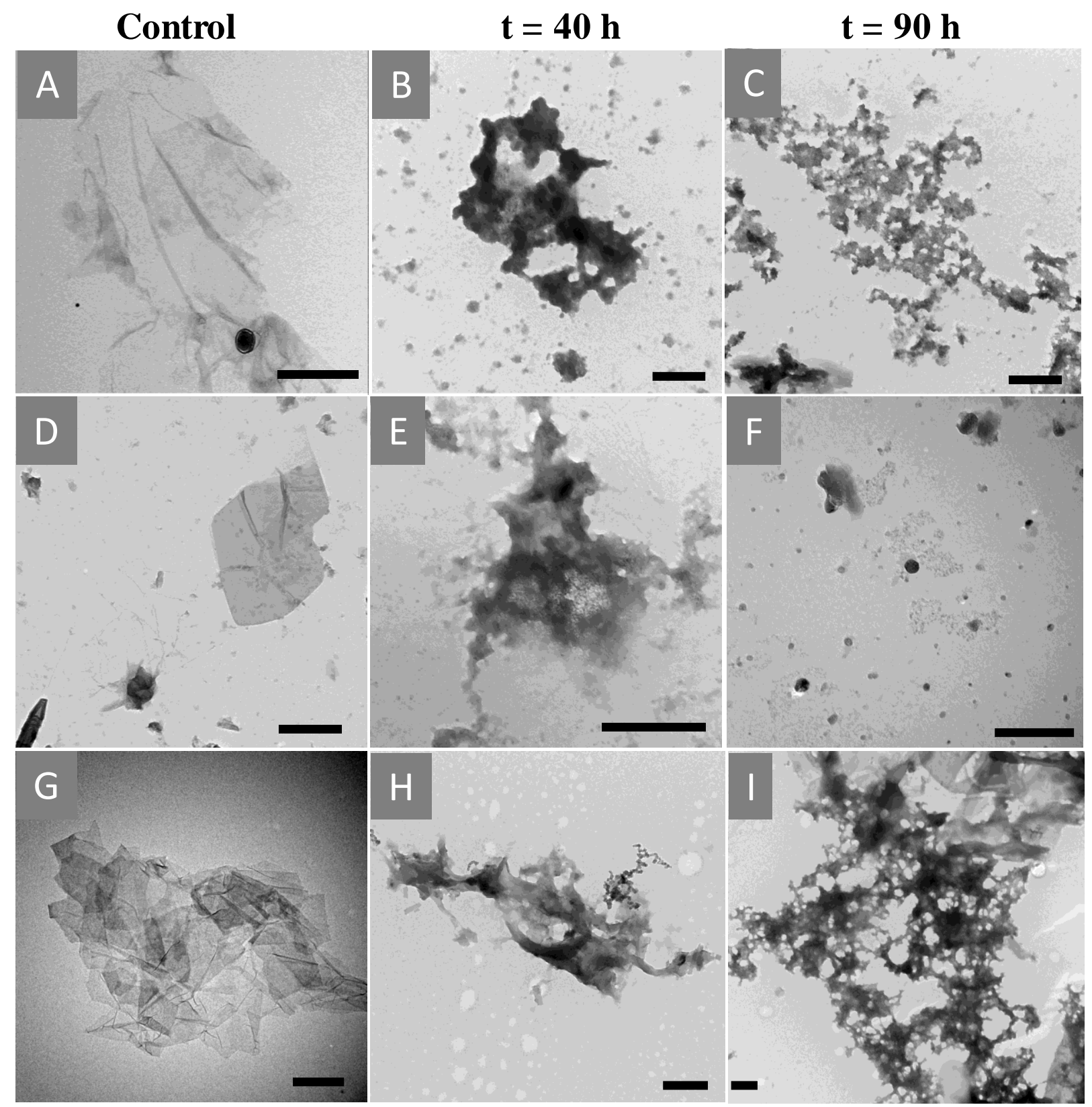

Figure 1: TEM images of EPO-catalyzed degradation of GO at three time points: control (in DI water, $t=0), t=40 \mathrm{~h}$, and $t=90 \mathrm{~h}$; images A-C correspond to GO $1, \mathrm{D}-\mathrm{F}$ correspond to GO 2 , and $\mathrm{G}-\mathrm{I}$ correspond to GO 3. Scale bar represents $500 \mathrm{~nm}$.

In addition, TEM along with selected area electron diffraction (SAED) analyses were employed to obtain more information about the crystalline patterns of GO. SAED let us to confirm the severe changes happening in the graphenic structure of GO sheets and the residual carbonaceous fragments after EPO treatment (Figure 2). The control sheets of samples GO 1, GO 2 and GO 3 
(after treating only with $\mathrm{H}_{2} \mathrm{O}_{2}$ for $90 \mathrm{~h}$, left column in Figure 2) display a typical ring-like SAED pattern along with a few diffraction spots representing the polycrystalline nature of GO sheets. ${ }^{23,24}$ These results also confirmed that control treatment did not damage or degrade GO sheets, in agreement with previous works. ${ }^{4,9}$ After $90 \mathrm{~h}$ of treatment with EPO in the presence of $\mathrm{H}_{2} \mathrm{O}_{2}$, the resulting carbonaceous fragments of GO 1 show different SAED pattern (Figure 2, right column). The resulting carbonaceous fragments of GO 1 consist of a highly porous morphology, which represents nearly amorphous structures as indicated by the diffusive diffraction pattern (Figure 2, inset) ${ }^{25}$ Similar kind of diffusive diffraction patterns were observed for GO 2 fragment after $90 \mathrm{~h}$ of treatment with EPO. In the case of GO 3, the amount of degraded fragments was lower in comparison to GO 1 and GO 2 (Figure 1), though nearly diffusive rings are present too (Figure 2), due to the partial degradation of GO 3. Overall, these results evidenced a higher resistance to degradation of GO 3 against EPO activity compared to GO 1 and GO 2 samples, likely due to a lower amount of oxygenated functions and consequently a less defective material. 

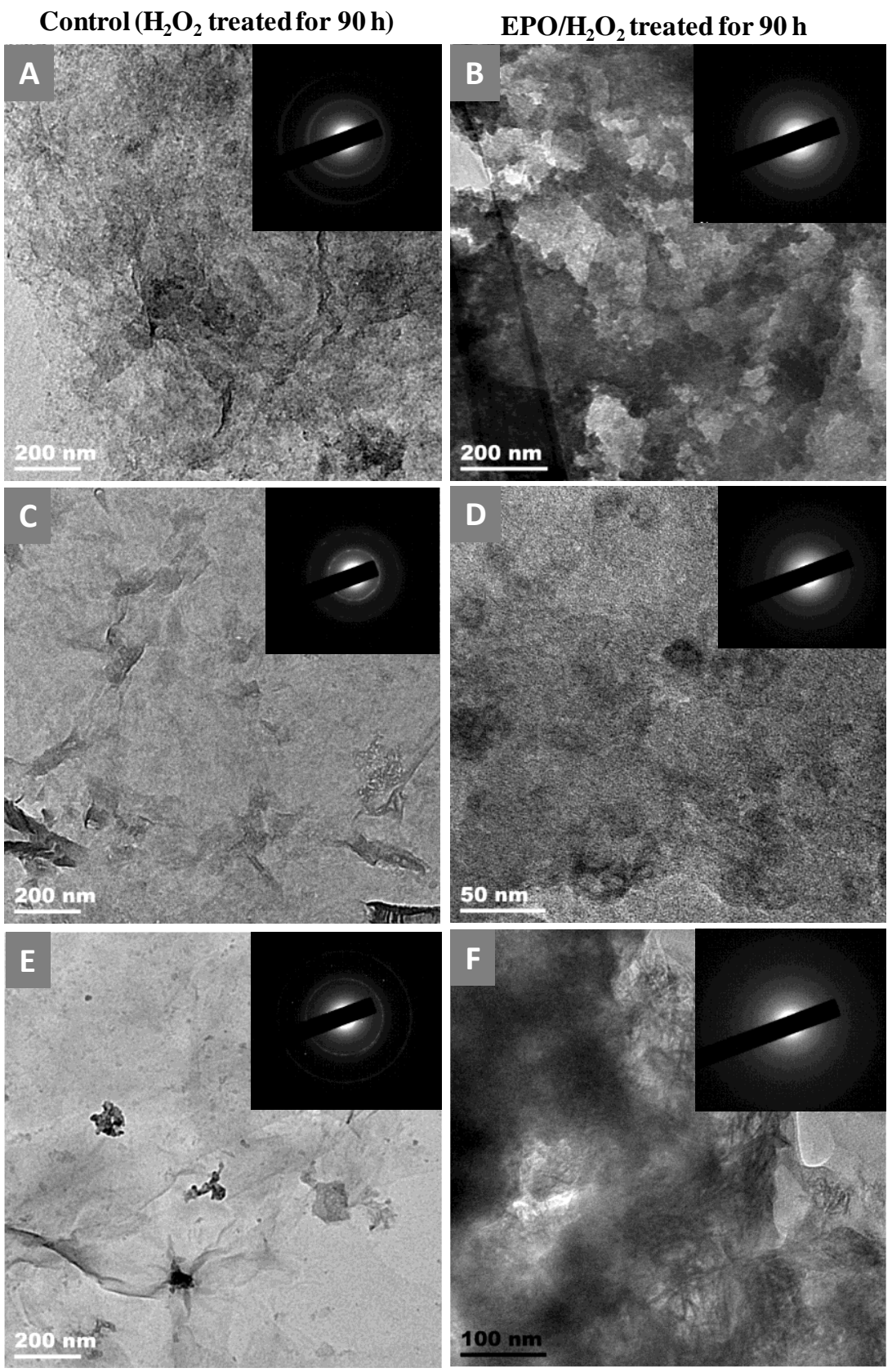

Figure 2: TEM analyses coupled to SAED. Images represent TEM along with diffraction patterns of GO 1, GO 2 and GO 3 sheets. Left column images (A), (C) and (E) show control GO sheets (treated only with $\mathrm{H}_{2} \mathrm{O}_{2}$ ) of GO 1, GO 2 and GO 3, respectively. Right column images (B), (D) and $(\mathrm{F})$ represent the residual carbonaceous fragments of GO 1, GO 2 and GO 3, respectively, after treatment with $\mathrm{EPO} / \mathrm{H}_{2} \mathrm{O}_{2}$ for $90 \mathrm{~h}$. SAED patterns are shown in the insets of each corresponding image. 
Next, we used Raman spectroscopy to analyze the structure of the three GO samples treated with EPO (Figure 3). The values of the ratio $\left(\mathrm{I}_{\mathrm{D}} / \mathrm{I}_{\mathrm{G}}\right)$ between the characteristic $\mathrm{D}$ band $\left(\sim 1350 \mathrm{~cm}^{-1}\right)$ and $\mathrm{G}$ band $\left(\sim 1600 \mathrm{~cm}^{-1}\right)$ provides information about the disorder in the graphitic lattice of the GO sheets. ${ }^{26}$ The control GO 1 and GO 2 have intense D and G bands at $0 \mathrm{~h}$ as shown with $\mathrm{I}_{\mathrm{D}} / \mathrm{I}_{\mathrm{G}}$ of $\sim 0.95$ and 0.78 , respectively (Figure $3 \mathrm{~A}$ and $3 \mathrm{~B}$ ).
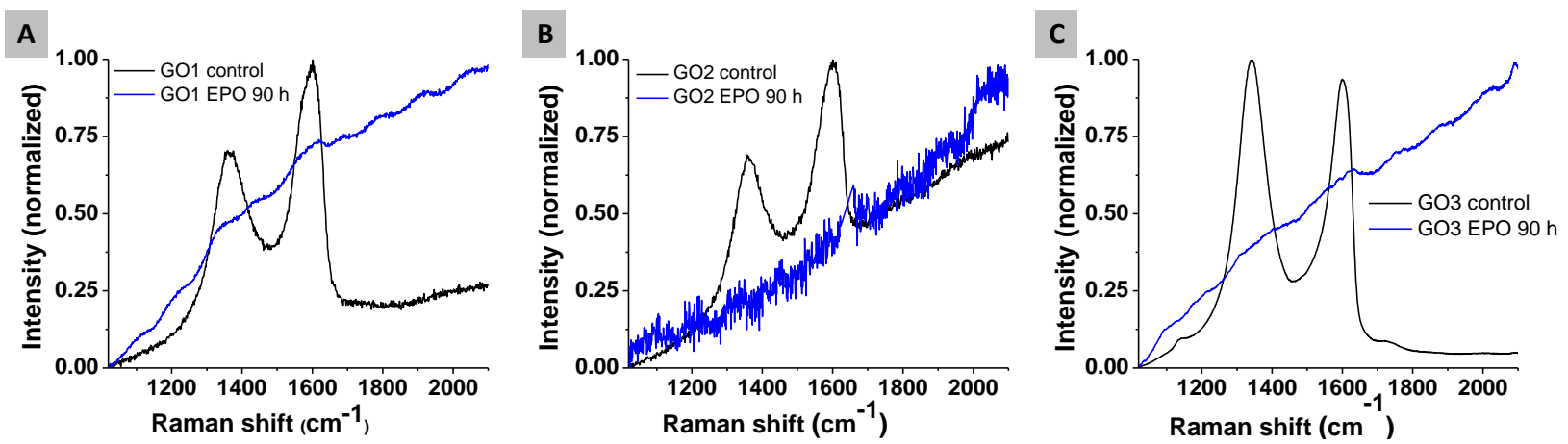

Figure 3: Average Raman spectra of (A) GO 1, (B) GO 2 and (C) GO 3. Control GO 1 and GO 2 $($ at $0 \mathrm{~h}$ ) are also shown (averages of at least five different spectra for each sample). For GO 3 the spectrum represents an average spectrum of the 2D Raman mapping analysis after $90 \mathrm{~h}$ of treatment with EPO (see Figure 5). The control sample treated with $\mathrm{H}_{2} \mathrm{O}_{2}$ alone is also represented.

However, after the treatment with EPO for $28 \mathrm{~h}$ (GO 1) and $30 \mathrm{~h}$ (GO 2), the D and G bands started losing their intensity, indicating the degradation or the oxidation was undergoing leading to the loss of the native nanomaterial structures (Figure 4). Furthermore, after $90 \mathrm{~h}$ of EPO treatment, the characteristic D and G band signals for GO 1 and GO 2 sheets were nearly absent. In the case of GO 1, very weak signals for the D and G the bands are present, suggesting that the degradation of GO 1 almost reached the completeness. Similar results, with the absence of D and G bands, were observed for the complete degradation of GO sheets after treating with both $\mathrm{HRP}^{9,11}$ and MPO${ }^{4}$.
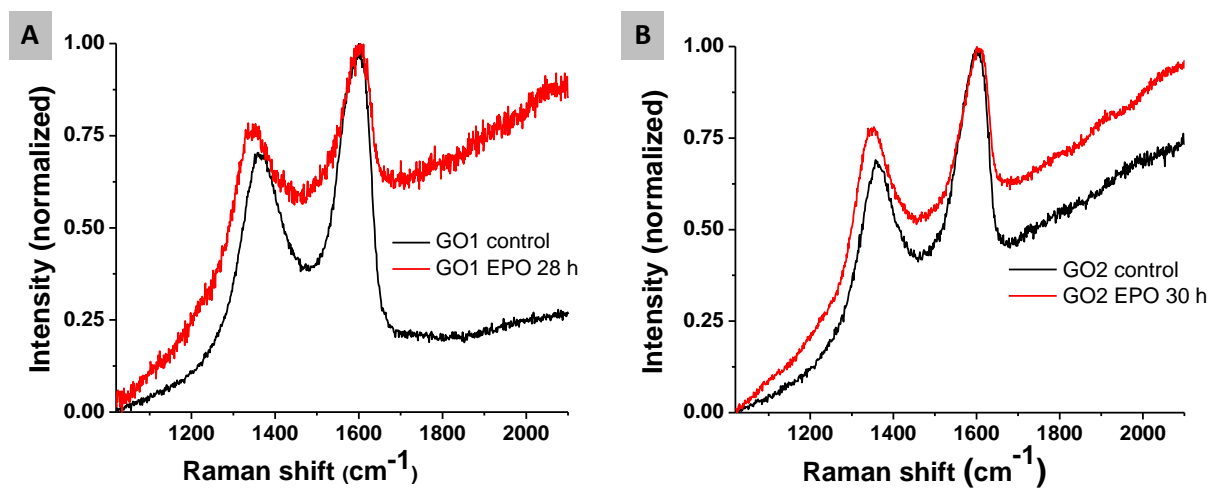
Figure 4: Average Raman spectra (at least $\mathrm{n}=5$ ) of GO 1 (A) and GO 2 (B). Spectra correspond to samples treated with EPO for $28 \mathrm{~h}$ and $30 \mathrm{~h}$, respectively. Control GOs (at $0 \mathrm{~h}$ ) are also shown.

For GO 3, intense $\mathrm{D}$ and $\mathrm{G}$ bands were observed after $90 \mathrm{~h}$ treatment with hydrogen peroxide, while the two bands nearly disappeared (with a little signal of D and G bands) after treating GO 3 with EPO for the same period, indicating again an extensive degradation of GO 3 sheets. 2D Raman mapping analysis also confirmed this result (Figure 5). Although the TEM results (Figure 1 and 2) and Raman analyses (Figure 3 and ) show the same trend, the degradation of GO 1 and GO 3 is not complete in comparison to GO 2 sheets, since slight D and G bands in the Raman spectra were present even after $90 \mathrm{~h}$ treatment. Moreover, Raman mapping of GO 3 suggest that degradation is not completed even after $90 \mathrm{~h}$ EPO treatment. XPS analysis (Table 1) showed that the percentage of graphitic carbon $\left(\mathrm{sp}^{2}\right)$ are $46 \%, 42 \%$ and $48 \%$ for GO 1, GO 2 and GO 3, respectively. These results confirm that GO 3 has highest graphitic regions or least defects over GO 1 and GO 2. The XPS results also revealed that GO 3 has lower number of carboxylic groups (1.0\%) compared to GO 1 (3.0\%) and GO 2 (1.5\%). The electrostatic binding of GO sheets with cationic EPO depends on the amount of carboxylic groups on the GO surface. The higher the number of oxygen groups, the better the degradation ability of the enzyme, as found in the case of degradation of GO and oxidized CNTs by MPO., ${ }^{47}$ Therefore the lower amount of carboxylic groups on GO 3 might be the reason for its uncomplete degradation after $90 \mathrm{~h}$ of incubation in the presence of EPO. The degradation of GO samples treated with EPO leads to the end-formation of $\mathrm{CO}_{2}$ (bubbling was observed during the process). We also expect the formation of intermediate byproducts consisting of polyaromatic molecules with oxygenated groups as reported in the literature. ${ }^{4,}{ }^{9} \mathrm{We}$ are currenty performing additional studies on the characterization of such fragments using LC-MS analysis, that will be reported in the near future. 

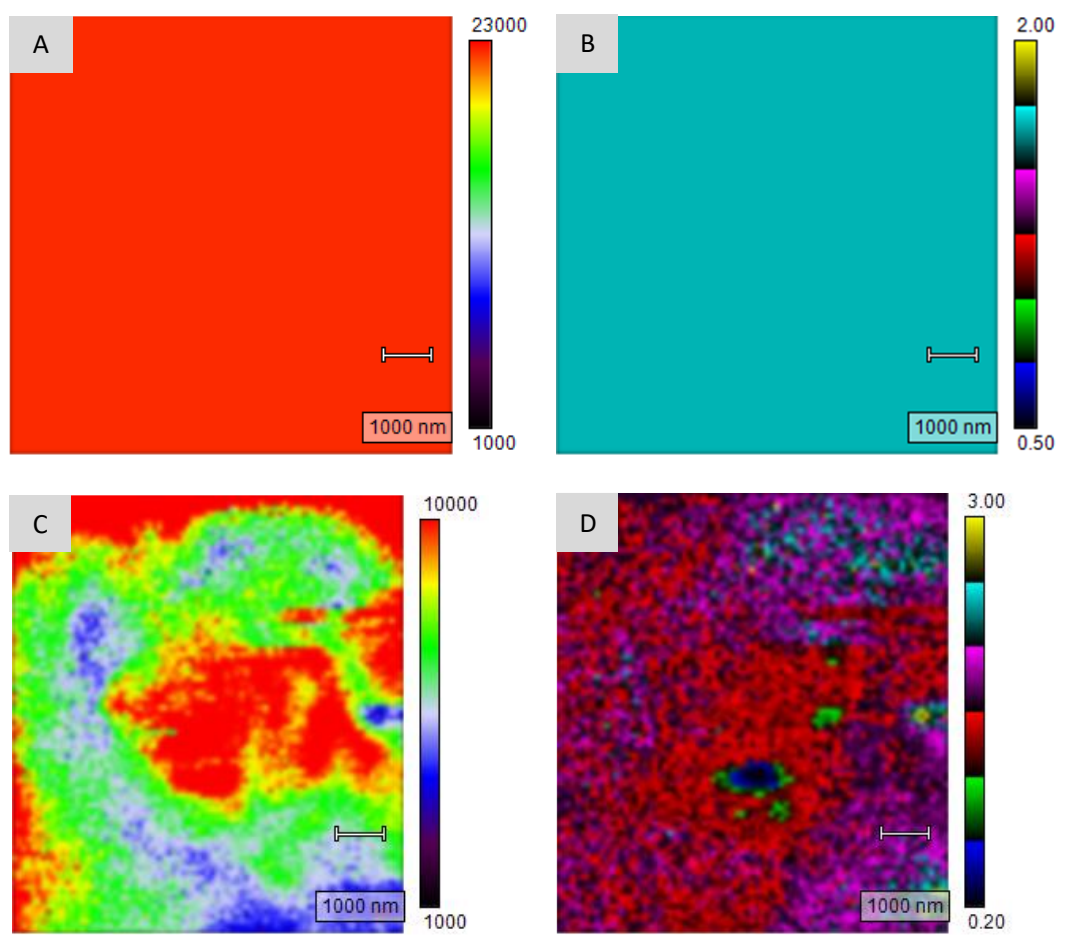

Figure 5: Raman 2D mapping of GO 3 sample. (A) and (B) represent $G$ band area map and D/G area ratio map of the control sample (after treating GO 3 with $\mathrm{H}_{2} \mathrm{O}_{2}$ for $90 \mathrm{~h}$ ), respectively; (C) and (D) represent $\mathrm{G}$ band area and $\mathrm{D} / \mathrm{G}$ area ratio maps of for EPO-treated sample (after incubation of GO 3 with $\mathrm{EPO}$ and $\mathrm{H}_{2} \mathrm{O}_{2}$ for $90 \mathrm{~h}$ ). The color bar intensity (which quantifies $\mathrm{G}$ band area) of control sample does not change due to the complete homogeneity. For control sample, the maps are highly uniform due to aggregation of the GO 3 sheets after $90 \mathrm{~h}$ of incubation in the buffer solution. However, after incubation of GO 3 with EPO, G band area intensity decreases in some parts of the enzyme treated sample, evidencing degraded parts of $\mathrm{GO} 3 . \mathrm{I}_{\mathrm{D}} / \mathrm{I}_{\mathrm{G}}$ area ratio varies as well only in the EPO treated GO 3, indicating again the biodegraded areas of the sample after 90 $\mathrm{h}$ of incubation.

Overall, our results confirm that human EPO is able to degrade GO effectively, similar to other human peroxidases, like MPO, in the presence of $\mathrm{H}_{2} \mathrm{O}_{2}$ and $\mathrm{NaBr}^{4}{ }^{4,6,17}$ However, the time of incubation in the presence of EPO that is needed to degrade GO is in general much longer ( $90 \mathrm{~h}$ ) compared to using MPO $(24 \mathrm{~h}){ }^{4}$ Similar results were also observed for oxidized SWCNTs, where the nanotubes were completely degraded within $90 \mathrm{~h}$ treatment by EPO..$^{15,17}$ The redox potentials of generated reactive intermediates of peroxidase enzymes play a key role in oxidation and eventually degradation of the graphitic materials. The redox potential of EPO (Compound I and Compound II) is slightly lower than MPO. The redox potential of EPO is $\sim 1.10 \mathrm{eV}$ against 1.16 $\mathrm{eV}$ for MPO. Moreover, MPO produces stronger oxidant species, like $\mathrm{HOCl}$, than $\mathrm{EPO}$, which 
produces HOBr. Therefore the degradation time is expected to be longer for EPO compared to MPO. ${ }^{15,27}$ The results also revealed that the degradation of GO sheets by EPO depends on the type of GO, and the respective methods of synthesis, which determine the number of oxygenated defects, similarly to the degradation of GO by MPO. ${ }^{4}$ Finally the results of this work emphasize that along with neutrophil secreted MPO, the eosinophil secreted EPO can degrade GFMs. This behavior could certainly help to better understand the biopersistency of GFMs.

In summary, biodegradation of GO is triggered by human eosinophil peroxidase in the presence of low concentration of $\mathrm{H}_{2} \mathrm{O}_{2}$ and $\mathrm{NaBr}$. The results confirm the degradation of $\mathrm{GO}$ samples by EPO treatment despite it is not completed after $90 \mathrm{~h}$ of treatment. It is important to note that the degradation of GO by this enzyme is dependent on the type of GO materials, in particular it is affected by the percentage of graphitic $\mathrm{sp}^{2}$ carbon and GO surface charge. As EPO is secreted by eosinophils, which are crucial immune cells playing an important role in allergic infections and asthma, the current results could help to better understand the interaction between GO and immune cells. These results are also helpful for the improvement on the design of useful biomedical products using GFMs.

\section{Current views and future directions}

Although assessing the biodegradation of GFMs is now very important for both reducing their toxicity to living organisms and removing them from the environment, the current studies are still at the infancy stage. The existing literature mainly concern the degradation of GFMs, and other 2D materials, mostly in test tube involving recombinant peroxidase, oxidative enzymes or oxidative conditions, and using in vitro immune cells (e.g. macrophages, neutrophils, eosinophils, etc.). Degradation of CNTs, GO and pristine graphene was clearly demonstrated at in vitro cellular level. ${ }^{9,15,27-30}$ So far, very limited studies have been reported on in vivo biodegradation, where the capacity of specific phagocytic cells or specific tissues are able to induce degradation of GFMs and 2D materials after their administration in animal models. ${ }^{12,31-35}$

Existing biodegradation studies on GFMs and 2D materials are not sufficient to properly understand their fate in living organisms and environment, due to limited number. Nevertheless, they provide crucial clues for the design and development of safe nanomaterials in biomedicine. ${ }^{36}$ The available literature suggests that degradation of the GFMs and other 2D materials is possible 
in vivo by the action of immune cells like neutrophils and macrophages. Until now, degradation of carbon nanomaterials and 2D materials, including hexagonal boron nitride $(\mathrm{hBN}),{ }^{5,37} \mathrm{MoS}_{2},{ }^{7,34}$, 35, 38, $39 \mathrm{WS}_{2},{ }^{40} \mathrm{MnO}_{2},{ }^{41}$ black phosphorous, ${ }^{42,}{ }^{43}$ has been reported. In addition, there are many other 2D materials like MXenes, graphitic $\mathrm{C}_{3} \mathrm{~N}_{4}, 2 \mathrm{D}$ clay materials, and others showing potential biomedical and environmental applications. ${ }^{44}$ However, the biodegradation studies of these emerging 2D materials have not been reported yet, except for a few materials (mentioned above). The biodegradation of GFMs is mainly dependent on the functionalization (oxidation) and the aqueous dispersibility of the material. Oxidized carbon nanomaterials (oxidized CNTs and GO) were shown to be degraded more easily than the pristine materials. ${ }^{9}, 17,45$ Compared to poorly aqueous-dispersible GFMs, the highly dispersible ones were found to be more degradable when treated with the peroxidases. ${ }^{4}$ In addition, the redox potential of peroxidase intermediates (Compound I and II in Figure 6, Table 2) and free radicals generated during enzymatic catalysis play a crucial role in the biodegradation of the GFMs and other 2D materials. ${ }^{46}$ For example, MPO degrades oxidized CNTs and GO within $24 \mathrm{~h}$, while HRP requires more than 20 days., ${ }^{4,17}$ This is due to the higher redox potential of MPO over HRP. The lessons learned from the biodegradation of GFMs were also nearly applicable to other 2D materials. We reported, for instance, that HRP does not degrade hBN up to 60 days, while MPO partially degrades hBN within $35 \mathrm{~h}$. An almost complete degradation of hBN leading to soluble boron oxide species occurred by photo-Fenton reaction in $100 \mathrm{~h}$. In addition, high-dispersible $\mathrm{hBN}$ was more degradable compared to the aggregated sheets. ${ }^{5,37} \mathrm{We}$ also examined the biodegradability of water dispersible pristine and functionalized $\mathrm{MoS}_{2}$ nanosheets. ${ }^{7}$ Exfoliated $\mathrm{MoS}_{2}$ sheets resulted more degradable than the functionalized materials by MPO. 


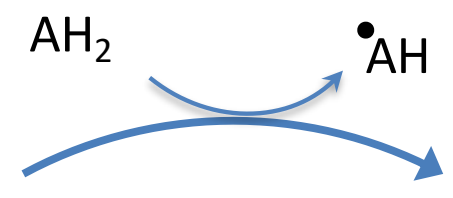

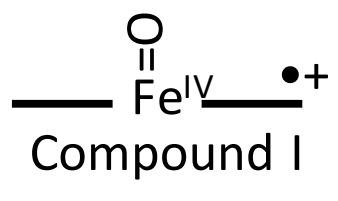

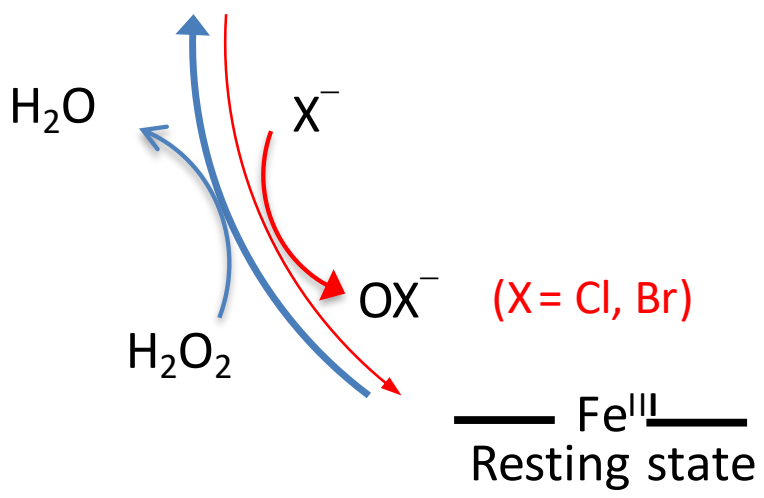

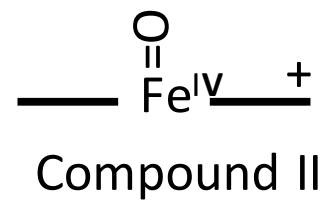

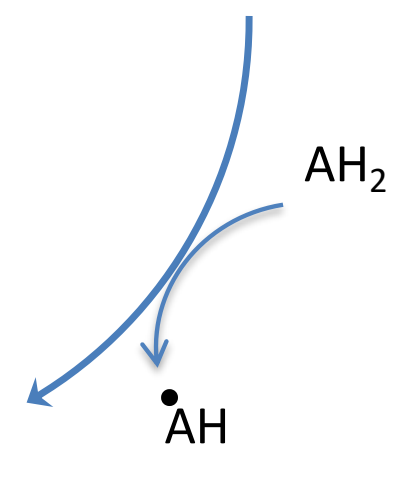

Figure 6: Peroxidase catalytic cycle of HRP (a plant enzyme) MPO and EPO (secreted by neutrophils and eosinophils) in the presence of hydrogen peroxide. Initially, the heme active site of the enzymes is at the resting state ( $\mathrm{Fe}^{\mathrm{III}}$ protoporphyrin IX heme group). After reacting with $\mathrm{H}_{2} \mathrm{O}_{2}$, the heme is converted to Compound I (ferryl oxo iron $\left(\mathrm{Fe}^{\mathrm{IV}+}=\mathrm{O}\right)$ ), a porphyrin $\pi$ cation radical, later it evolves to Compound II and it returns to the resting state. For MPO Compound I is reduced directly to the resting state by reacting with $\mathrm{Cl}^{-}$to form $\mathrm{HOCl}$. (This figure and table are adapted from reference ${ }^{46}$ ).

Table 2: Redox Potentials of HRP, MPO and EPO intermediates during peroxidase cycle

\begin{tabular}{|l|l|l|}
\hline Enzyme & State of peroxidase cycle & $E^{0}(\mathrm{~V})$ \\
\hline HRP & Compound I/Compound II & 0.94 \\
& Compound II/Resting state & 0.96 \\
\multirow{3}{*}{ MPO } & Compound I/Resting state & 1.16 \\
& Compound I/Compound II & 1.35 \\
\hline EPO & Compound II/resting state & 0.97 \\
\hline
\end{tabular}


Besides peroxidase-based studies, there are also reports discussing the possible degradation of GFMs by different types of microbes including bacteria and fungi. In one of the first studies, Liu et al. reported that a naphthalene-degrading bacterial strain isolated from the contaminated soil in a graphite mine is able to oxidize graphite, $\mathrm{GO}$ and reduced graphene oxide (rGO). ${ }^{47}$ After 14 days incubation with bacteria, rGO was found to be degraded more than graphite since rGO had more defects and higher surface area than graphite, while GO was degraded into small pieces resulting in holey GO sheets. Zhu et al. have reported the microbial oxidation of graphite by Acidithiobacillus ferrooxidans CFMI-1 bacteria, ${ }^{48}$ while Zhang et al. demonstrated that a bacterial community, made of Burkholderia kururiensis, Delftia acidovorans, and Stenotrophomonas maltophilia, is capable of degrading ${ }^{14} \mathrm{C}$-labeled MWCNTs into ${ }^{14} \mathrm{CO}_{2}$ in the presence of an external carbon source via co-metabolism. ${ }^{49}$ Other soil bacteria, like Trabusiella guamensis has also shown oxidation-mediated degradation of MWCNTs. ${ }^{50}$ Trametes versicolor and natural microbial cultures were used for the biotransformation of SWCNTs. ${ }^{51}$ Based on the results on CNTs, white-rot fungi like Phanerochaete chrysosporium were also employed to assess the biodegradation of other GFMs. ${ }^{52}$

Moreover, as these microbial enzymes are cheaper compared to peroxidase enzymes, microbialmediated degradation could be more convenient to understand the degradation of 2D materials. In addition to peroxidase enzymes and microbial enzymes, more recently we have found that the artificial peroxidases mimicking enzyme known as "DNAzymes" composed of a guanine rich Gquadruplex (a single-stranded DNA complexed to hemin), can degrade GO similar to HRP (a plant enzyme). ${ }^{53}$ These peroxidase mimicking DNAzymes could be useful to understand the degradation reactions of carbon nanomaterials for longer time compared to peroxidase enzymes, since the DNAzymes have the better stability for months at ambient temperature unlike natural enzymes.

Recently, we have demonstrated a novel strategy called "degradation-by-design" of GFMs, ${ }^{8}$ which involves covalent functionalization with specific molecules able to enhance the catalytic activity of peroxidases. This strategy was successfully applied to GO. ${ }^{54}$ Two specific ligands, namely7hydroxy azido coumarin (AZC) and 3,4-dihydroxybenzoic acid (DHBA) were covalently linked to CNTs and GO to enhance the enzymatic action of HRP either by attracting the enzyme in close proximity of its active site or by mediating the electron transfer between CNTs or GO and the enzyme, thereby leading to the increase of the oxidation rate. In this regard, future chemical 
functionalization of GFMs and other 2D materials can be designed aimed to combine the biomedical applications of carbon materials with a controlled biodegradability.

In conclusion, further in vivo studies have to be done to properly understand the fate of GFMs and other 2D materials in animal models, despite the bottlenecks that this aim entails regarding the follow-up of degradation in vivo. Thankfully, the existing biodegradation studies provide crucial clues for the design and development of safe nanomaterials in biomedicine and pave the way for future new experiments. In a few words, the critical validation tests should be extended to whole model organisms. Along this line, further studies to extend the knowledge about biodegradation of $2 \mathrm{D}$ material in the environment, considering representative microorganisms and comparable conditions to the real environmental situations, have to be performed. In these contexts, the development of novel artificial enzymes that mimic the natural ones would help to reach these goals.

\section{Experimental Section}

\section{Materials}

Graphene oxide sample GO 1 was prepared using a modified Hummers method. ${ }^{19}$ Graphene oxide sample GO 2 was purchased from Grupo Antolin (Spain). GO 3 was also prepared using a modified Hummers method. ${ }^{21}$ EPO derived from human neutrophils (Athens Research and Technology, USA) with an activity of greater than 180 units per $\mathrm{mg}$ protein after lyophilization. Hydrogen peroxide (30\% aqueous solution), $\mathrm{NaBr}, \mathrm{NaH}_{2} \mathrm{PO}_{4} \cdot 2 \mathrm{H}_{2} \mathrm{O}$ and $\mathrm{Na}_{2} \mathrm{HPO}_{4} \cdot 2 \mathrm{H}_{2} \mathrm{O}$ were purchased from Alfa Aesar and used directly without any further purification.

\section{Degradation of GO by EPO/ $\mathrm{H}_{2} \mathrm{O}_{2}$}

Fifteen $\mu \mathrm{g}$ of each GO sample (GO 1, GO 2 and GO 3) were dispersed in $50 \mu \mathrm{L}$ of $100 \mathrm{mM}$ phosphate buffer followed by addition of $50 \mu \mathrm{g}$ of human EPO (pre-dissolved in $50 \mu \mathrm{L}$ of $100 \mathrm{mM}$ phosphate buffer) to each $\mathrm{GO}$ suspension. Both $\mathrm{H}_{2} \mathrm{O}_{2}$ and $\mathrm{NaBr}$ were added at $100 \mu \mathrm{M}$ per hour for 90 , corresponding to $2 \mu \mathrm{l}$ of $5 \mathrm{mM}$ of $\mathrm{H}_{2} \mathrm{O}_{2}$ and $5 \mathrm{mM}$ of $\mathrm{NaB}$, respectively. The reaction mixture was maintained at $37{ }^{\circ} \mathrm{C}$ for $90 \mathrm{~h}$ in a cell incubator. Five $\mu \mathrm{g}$ of EPO were added every $12 \mathrm{~h}$. The control experiments only adding $\mathrm{H}_{2} \mathrm{O}_{2}$ were also performed using the same protocol. 


\section{Raman spectroscopy}

Raman analysis of all the GO samples was performed using Renishaw inVia microRaman equipped with $532 \mathrm{~nm}$ laser and a Leica microscope. All the spectra were recorded with $5 \%$ laser power using a 50x objective lens. All samples for Raman analyses were prepared by drop-casting $10 \mu \mathrm{L}$ of respective samples on $\mathrm{SiO}_{2}$ wafer and dried for $24 \mathrm{~h}$ at room temperature.

Raman 2D mapping of GO 3 samples was carried out using Raman spectra Renishaw inVia microRaman equipped with a $532 \mathrm{~nm}$ laser. Sample was dried on the $\mathrm{SiO}_{2}$ microscopic slides and 2D mapping was performed at with $1 \%$ laser power using a $100 \times$ objective lens.

\section{Transmission electron microscopy}

For TEM characterization, $6 \mu \mathrm{L}$ of each suspension of GO were deposited on a carbon coated copper grids and dried for $24 \mathrm{~h}$ before the analysis. All the samples were analyzed by a Hitachi H7500 microscope (Tokyo, Japan) with an accelerating voltage of $80 \mathrm{kV}$, equipped with a AMT Hamamatsu camera (Tokyo, Japan). SAED-coupled TEM analyses were performed on a JEOL 2100F TEM/STEM electron microscope operating at $200 \mathrm{kV}$.

X-ray photoelectron spectroscopy: GO 3 sample was dried on the silicon wafer and XPS analyses were carried out using K-ALPHA Surface Analysis spectrophotometer (Thermo Scientific). Three different spectra were collected for each sample.

Zeta potential measurement: Zeta potential of GO 1, GO 2, and GO 3 were performed using Zetasizer Nano S (Malvern Instruments) spectrometer operating under $633 \mathrm{~nm}$ laser irradiation. All zeta potentials of GO dispersions were measured at $\mathrm{pH} 7$.

\section{Acknowledgements}

This work was supported by the Centre National de la Recherche Scientifique (CNRS), by the Agence Nationale de la Recherche (ANR) through the LabEx project Chemistry of Complex Systems (ANR-10-LABX-0026_CSC) and by the International Center for Frontier Research in Chemistry (icFRC). The authors gratefully acknowledge financial support from EU Commission through the GRAPHENE Flagship project (no. 696656 and no. 785219)). We wish to acknowledge Cathy Royer and Valérie Demais for TEM analyses at the Plateforme Imagerie in Vitro at the Center of Neurochemistry (INCI, Strasbourg, France). Grupo Antolin (Spain) is also greatly acknowledged for providing the material. We would also like to thank Dris Ihiawakrim for SAED analysis. 


\section{ORCID}

Rajendra Kurapati: https://orcid.org/0000-0002-1811-2428

Cristina Martín: https://orcid.org/0000-0001-5670-3328

Yuta Nishina: https://orcid.org/0000-0002-4958-1753

Alberto Bianco: https://orcid.org/0000-0002-1090-296X

\section{References}

1. G. Reina, J. M. Gonzalez-Dominguez, A. Criado, E. Vazquez, A. Bianco and M. Prato, Chem. Soc. Rev., 2017, 46, 4400-4416.

2. B. Fadeel, C. Bussy, S. Merino, E. Vázquez, E. Flahaut, F. Mouchet, L. Evariste, L. Gauthier, A. J. Koivisto, U. Vogel, C. Martín, L. G. Delogu, T. Buerki-Thurnherr, P. Wick, D. Beloin-Saint-Pierre, R. Hischier, M. Pelin, F. Candotto Carniel, M. Tretiach, F. Cesca, F. Benfenati, D. Scaini, L. Ballerini, K. Kostarelos, M. Prato and A. Bianco, ACS Nano, 2018, 12, 10582-10620.

3. R. Kurapati, K. Kostarelos, M. Prato and A. Bianco, Adv. Mater., 2016, 28, 6052-6074.

4. R. Kurapati, J. Russier, M. A. Squillaci, E. Treossi, C. Ménard-Moyon, A. E. Del RioCastillo, E. Vazquez, P. Samorì, V. Palermo and A. Bianco, Small, 2015, 11, 3985-3994.

5. R. Kurapati, C. Backes, C. Ménard-Moyon, J. N. Coleman and A. Bianco, Angew. Chem. Int. Ed., 2016, 55, 5506-5511.

6. R. Kurapati, S. P. Mukherjee, C. Martín, G. Bepete, E. Vázquez, A. Pénicaud, B. Fadeel and A. Bianco, Angew. Chem. Int. Ed., 2018, 57, 11722-11727.

7. R. Kurapati, L. Muzi, A. P. R. de Garibay, J. Russier, D. Voiry, I. A. Vacchi, M. Chhowalla and A. Bianco, Adv. Funct. Mater., 2017, 27, 1605176.

8. A. R. Sureshbabu, R. Kurapati, J. Russier, C. Ménard-Moyon, I. Bartolini, M. Meneghetti, K. Kostarelos and A. Bianco, Biomaterials, 2015, 72, 20-28.

9. G. P. Kotchey, B. L. Allen, H. Vedala, N. Yanamala, A. A. Kapralov, Y. Y. Tyurina, J. Klein-Seetharaman, V. E. Kagan and A. Star, ACS Nano, 2011, 5, 2098-2108.

10. G. Lalwani, W. Xing and B. Sitharaman, Journal of Materials Chemistry B, 2014, 2, 63546362. 
11. R. Kurapati, F. Bonachera, J. Russier, A. R. Sureshbabu, C. Ménard-Moyon, K. Kostarelos and A. Bianco, 2D Materials, 2017, 5, 015020.

12. C. M. Girish, A. Sasidharan, G. S. Gowd, S. Nair and M. Koyakutty, Adv. Healthc. Mater., 2013, 2, 1489-1500.

13. C. Martín, A. Ruiz, S. Keshavan, G. Reina, D. Murera, Y. Nishina, B. Fadeel and A. Bianco, Adv. Funct. Mater., 2019, 29, 1901761.

14. A. A. Khan, A. H. Rahmani, Y. H. Aldebasi and S. M. Aly, Global journal of health science, 2014, 6, 87-98.

15. F. T. Andõn, A. A. Kapralov, N. Yanamala, W. Feng, A. Baygan, B. J. Chambers, K. Hultenby, F. Ye, M. S. Toprak, B. D. Brandner, A. Fornara, J. Klein-Seetharaman, G. P. Kotchey, A. Star, A. A. Shvedova, B. Fadeel and V. E. Kagan, Small, 2013, 9, 2721-2729.

16. J.-Y. Lacoste, J. Bousquet, P. Chanez, T. Van Vyve, J. Simony-Lafontaine, N. Lequeu, P. Vic, I. Enander, P. Godard and F. o.-B. Michel, Glob. J. Health Sci., 1993, 92, 537-548.

17. V. Kagan, N. Konduru, W. Feng, B. Allen, J. Conroy, Y. Volkov, I. Vlasova, N. Belikova, N. Yanamala, A. Kapralov, Y. Tyurina, J. Shi, E. Kisin, A. Murray, J. Franks, D. Stolz, P. Gou, J. Klein-Seetharaman, B. Fadeel, A. Star and A. Shvedova, Nat. Nanotechnol., 2010, 5, $354-359$.

18. E. Treossi, M. Melucci, A. Liscio, M. Gazzano, P. Samorì and V. Palermo, JACS, 2009, 131, 15576-15577.

19. J. Russier, E. Treossi, A. Scarsi, F. Perrozzi, H. Dumortier, L. Ottaviano, M. Meneghetti, V. Palermo and A. Bianco, Nanoscale, 2013, 5, 11234-11247.

20. N. Morimoto, H. Suzuki, Y. Takeuchi, S. Kawaguchi, M. Kunisu, C. W. Bielawski and Y. Nishina, Chem. Mater., 2017, 29, 2150-2156.

21. N. Morimoto, T. Kubo and Y. Nishina, Sci. Rep., 2016, 6, 21715.

22. H. Varela-Rizo, I. Rodriguez-Pastor, C. Merino and I. Martin-Gullon, Carbon, 2010, 48, 3640-3643.

23. H.-K. Jeong, Y. P. Lee, R. J. W. E. Lahaye, M.-H. Park, K. H. An, I. J. Kim, C.-W. Yang, C. Y. Park, R. S. Ruoff and Y. H. Lee, JACS, 2008, 130, 1362-1366.

24. K. Krishnamoorthy, M. Veerapandian, K. Yun and S. J. Kim, Carbon, 2013, 53, 38-49.

25. D. C. Marcano, D. V. Kosynkin, J. M. Berlin, A. Sinitskii, Z. Sun, A. Slesarev, L. B. Alemany, W. Lu and J. M. Tour, ACS Nano, 2010, 4, 4806-4814. 
26. M. S. Dresselhaus, A. Jorio, M. Hofmann, G. Dresselhaus and R. Saito, Nano Lett., 2010, 10, 751-758.

27. K. Bhattacharya, S. P. Mukherjee, A. Gallud, S. C. Burkert, S. Bistarelli, S. Bellucci, M. Bottini, A. Star and B. Fadeel, Nanomed. Nanotechnol. Biol. Med., 2016, 12, 333-351.

28. J. Russier, C. Ménard-Moyon, E. Venturelli, E. Gravel, G. Marcolongo, M. Meneghetti, E. Doris and A. Bianco, Nanoscale, 2011, 3, 893-896.

29. C. F. Chiu, H. H. Dar, A. A. Kapralov, R. A. S. Robinson, V. E. Kagan and A. Star, Nanoscale, 2017, 9, 5948-5956.

30. S. P. Mukherjee, A. R. Gliga, B. Lazzaretto, B. Brandner, M. Fielden, C. Vogt, L. Newman, A. F. Rodrigues, W. Shao, P. M. Fournier, M. S. Toprak, A. Star, K. Kostarelos, K. Bhattacharya and B. Fadeel, Nanoscale, 2018, 10, 1180-1188.

31. Y. Sato, A. Yokoyama, Y. Nodasaka, T. Kohgo, K. Motomiya, H. Matsumoto, E. Nakazawa, T. Numata, M. Zhang, M. Yudasaka, H. Hara, R. Araki, O. Tsukamoto, H. Saito, T. Kamino, F. Watari and K. Tohji, Sci. Rep., 2013, 3, 2516.

32. A. Nunes, C. Bussy, L. Gherardini, M. Meneghetti, M. A. Herrero, A. Bianco, M. Prato, T. Pizzorusso, K. T. Al-Jamal and K. Kostarelos, Nanomedicine, 2012, 7, 1485-1494.

33. I. I. Vlasova, A. V. Sokolov, A. V. Chekanov, V. A. Kostevich and V. B. Vasilyev, Russ. J. Bioorganic Chem., 2011, 37, 453.

34. L. Mei, X. Zhang, W. Yin, X. Dong, Z. Guo, W. Fu, C. Su, Z. Gu and Y. Zhao, Nanoscale, 2019, 11, 4767-4780.

35. L. Chen, Y. Feng, X. Zhou, Q. Zhang, W. Nie, W. Wang, Y. Zhang and C. He, ACS Appl. Mater. Interfaces, 2017, 9, 17347-17358.

36. M. Chen, X. Qin and G. Zeng, Trends Biotechnol., DOI: 10.1016/j.tibtech.2016.12.001.

37. R. Kurapati, C. Backes, C. Ménard-Moyon, J. N. Coleman and A. Bianco, Angew. Chem., 2016, 128, 5596-5601.

38. B. Wu, L. Chen, X. Wu, H. Hou, Z. Wang and S. Liu, Environmental Science: Nano, 2019, 6, 1594-1606.

39. X. Zhou, J. Jia, Z. Luo, G. Su, T. Yue and B. Yan, ACS Appl. Mater. Interfaces, 2019, 11, 6829-6839.

40. X. Zhou and B. Yan, Nanoscale, 2019, 11, 10684-10694. 
41. Z.-L. Song, X. Dai, M. Li, H. Teng, Z. Song, D. Xie and X. Luo, Microchimica Acta, 2018, $185,485$.

42. S. Kuriakose, T. Ahmed, S. Balendhran, V. Bansal, S. Sriram, M. Bhaskaran and S. Walia, 2D Materials, 2018, 5, 032001.

43. S. Wu, F. He, G. Xie, Z. Bian, J. Luo and S. Wen, Nano Lett., 2018, 18, 5618-5627.

44. C. Martin, K. Kostarelos, M. Prato and A. Bianco, Chem. Commun., 2019, DOI: 10.1039/C9CC01205B.

45. B. L. Allen, P. D. Kichambare, P. Gou, I. I. Vlasova, A. A. Kapralov, N. Konduru, V. E. Kagan and A. Star, Nano Lett., 2008, 8, 3899-3903.

46. G. P. Kotchey, S. A. Hasan, A. A. Kapralov, S. H. Ha, K. Kim, A. A. Shvedova, V. E. Kagan and A. Star, Acc. Chem. Res., 2012, 45, 1770-1781.

47. L. Liu, C. Zhu, M. Fan, C. Chen, Y. Huang, Q. Hao, J. Yang, H. Wang and D. Sun, Nanoscale, 2015, 7, 13619-13628.

48. C. Zhu, L. Liu, M. Fan, L. Liu, B. Dai, J. Yang and D. Sun, RSC Advances, 2014, 4, 5504455047.

49. L. Zhang, E. J. Petersen, M. Y. Habteselassie, L. Mao and Q. Huang, Environ. Pollut., 2013, 181, 335-339.

50. R. S. Chouhan, A. Qureshi, B. Yagci, M. A. Gülgün, V. Ozguz and J. H. Niazi, Chem. Eng. J., 2016, 298, 1-9.

51. A. N. Parks, G. T. Chandler, K. T. Ho, R. M. Burgess and P. L. Ferguson, Environ. Toxicol. Chem., 2015, 34, 247-251.

52. H. Yang, X. Wu, Q. Ma, A. Yilihamu, S. Yang, Q. Zhang, S. Feng and S.-T. Yang, Chemosphere, 2019, 216, 9-18.

53. R. Kurapati and A. Bianco, Nanoscale, 2018, 10, 19316-19321.

54. R. Kurapati, F. Bonachera, J. Russier, A. R. Sureshbabu, C. Ménard-Moyon, K. Kostarelos and A. Bianco, 2D Materials, 2018, 5, 015020. 